gangen ist, während die Verbrühungsstatistik einer jeden grösseren Stadt Ihnen genügende Beweismaterialien liefern wird, dass Kinder bei viel weniger in - und extensiven Verbrennungen ihr Leben unmittelbar oder bald darauf einbüssen.

Besser, sebr geehrter College, als durch Reflexionen und Deductionen werden Sie daher von der Wahrhaftigkeit meiner Ergebnisse und von der Unbaltbarkeit Ihrer Hypothese sich überzeugen, wenn Sie die Mühe nicht schenen wollen, meine Befunde experimentell noch elnmal zu prüfen. Und ich kann Sie versichern, dass schon wenige Versuche Sle zum Ziele führen werden. - Ich zweifte auch nichi; dass Sie dann keinen Anstand nehmen werden, bei hochgradigen Verbrennungen die Transfusion als einziges lebensrettendes Mittel zu erproben. -

Für Ihre experimentellen Nachprüfungen wünsche ich aber, dass Sie.verschont bleiben mögen von der Meute anonymer Freibeuter, die durch Verläumdungen die Menge aufzuregen nnd das Urtheil der Gebildeteren irre zu fübren suchen.

5.

\title{
Ueber Schrumpliniere.
}

Entgegnung auf den offenen Brief der Herren Dr. P. Grawitz und Dr. O. Israel (Bd. LXXX. S. 379).

Von prof. Dr. Heller in Kiel.

Mein (durch einen redactionellen Missgriff in. Form einer besonderen Mittheilung abgedrucktes) Referat über einen im physiologischen Vereine unter Vorlegung von mikroskopischen Präparaten gehaltenen Vortrag hat eine Entgegnung von Ihrer Seite erfabren, welche das Wesentliche meiner Kritik umgeht.

Es waren drei Punkte, um die es sich handelte. Erstens fehlt vorläufig jede Berechtigung, die atrophischen Nieren Ihrer Versuchsthiere mit den menschlichen Schrumpfnieren zu identificiren. Es herrscht volle Uehereinstimmung, dass bei diesen die Glomeruli mebr oder weniger stark verödet gefunden werden; Zeuge dafür die Lehrbücher der pathologischen Anatomie, die doch den jeweiligen Stand der Lehre wiedergeben. Dem gegenüber sagen Sie: „nur die Glomeruli verharren in auffallender Integrität" (S. 32\%, Bd. 77) in Bezug auf die einen und: „auch bei dieser Affection erhalten sich die Glomeruli sehr resistent, wir haben an ihnen keinerlei Veränderungen wahrgenommen " (S. 323).

Zweitens berücksichtigten Sie in Ihrer Polemik gegen Bartels viur dessen 1871 in Vortragsform erschienene Mittheilung (Klinische Vorträge, herausgegeben von Volkmann), während diese Polemik eben durch die ausführliche Arbeit (v. Ziemssen's Handbuch IX. 1875) grösstentheils hinfällig geworden ist.

Drittens endlich hob ich hervor, dass Bartels durchaus Schrumpfnieren anderen Ursprungs nicht leugnete; dass der Kern seiner Lehre durch histologische und experimentelle Arbeiten nicht zu erschüttern ist; der Satz, auf den es ihm ankam, ist doch nur der klinische, dass es nicht wahr ist, dass die an Schrumpfnieren Sterbenden anfangs ein Stadium mit den klinischen Erscheinungen der „parenchymatösen Nephritis" durchgemacht haben. Wer diesen Satz bekämpfen will, muss ihn mit ebenbürtigen klinischen Beobachtungen bekämpfen; dies dürfte den Jahrzehnte lang fortgesetzten gewissenhaften Beobachtungen gegenüber, über welche Bartels verfügte, nicht leicht sein; seine Kranken gebörten zum Theil den besten Kreisen der Bevölkerung an, deren ganzes früheres Leben vollkommen klar vorlag.

Im Uebrigen muss ich auf eine demnächst zum Abschluss kommende Bearbeitung des reichhaltigen, mir zu Gebote stehenden Materiales verweisen. 